\title{
JURISPRUDENCIA AMBIENTAL EN LA COMUNIDAD DE MADRID (SEGUNDO SEMESTRE 2017)
}

\author{
ANTONIO FORTES MARTíN \\ Profesor titular de Derecho Administrativo \\ Universidad Carlos III de Madrid
}


Sumario: 1. Necesaria precedencia de la declaración de impacto ambiental sobre la autorización ambiental integrada. 2. Ordenanza municipal y límite de emisiones de los vehículos autotaxi.

\section{Necesaria precedencia de la declaración de impacto ambiental sobre la autorización ambiental integrada.}

La Sentencia núm 1298/2017 de la Sala de lo contencioso-administrativo del Tribunal Supremo (TS), de 18 de julio de 2017, resuelve el recurso de casación presentado por una asociación de vecinos y una asociación ecologista contra la Sentencia de la Sala de lo contencioso-administrativo del Tribunal Superior de Justicia de Madrid (TSJM) de 2 de junio de 2016 que, en su día, desestimó el recurso contencioso-administrativo interpuesto por las ahora recurrentes en casación.

El interés de la Sentencia radica en el alcance, tanto de la modificación sutancial de la autorización ambiental integrada en el regimen de prevención y control integrados de la contaminación, como de la declaración de impacto ambiental para una fábrica de cementos como instalación industrial objeto de la controversia. Concretamente, los recurrentes cuestionan ahora, en sede casacional, la tramitación y resolución simultánea y conjunta del trámite de evaluación de impacto ambiental y la autorización ambiental integrada por parte de la Comunidad de Madrid, lo que, a su modo de ver, plantea un supuesto de nulidad de pleno derecho del artículo 62.1.e) de la Ley 30/1992, de 26 de noviembre (hoy día artículo 47.1.e) de la Ley 39/2015, de 1 de octubre).

La Comunidad de Madrid, en una única Resolución, ordenó publicar la autorización ambiental integrada y la declaración de impacto ambiental pese a tratarse de instrumentos de protección ambiental diferenciados y con fines distintos.

Así pues, lo que se cuestiona es si el trámite de evaluación ambiental ha de realizarse con carácter previo al otorgamiento de la correspondiente autorización ambiental integrada, y si la declaración de impacto ambiental, como culminación de dicho trámite, debe emitirse y publicarse en todo caso, y preceptivamente con carácter previo al otorgamiento de la meritada 
autorización ambiental integrada.

El máximo órgano jurisdiccional resuelve la cuestión a partir de un pronunciamiento similar previo de 9 de julio de 2015 donde, sin entrar en la legislación autonómica, el TS apreció entonces, y también ahora en el caso que nos ocupa, "vulneración de las exigencias dispuestas por la normativa europea, sobre todo, y también por la normativa estatal básica". El fallo de 9 de julio de 2015 abordaba de lleno la cuestión de la exigencia de publicación de la declaración de impacto ambiental con carácter previo al otorgamiento de la autorización ambiental. Y el TS se cuestionó para ello la finalidad a la que realmente sirve la satisfacción de ese trámite de evaluación ambiental. De forma sucesiva, el Alto Tribunal va desgranando pormenorizadamente qué pretende y cómo la declaración de impacto ambiental y cuándo debe producirse la misma. En este sentido, es de destacar, en palabras del propio TS:

"que el trámite de evaluación ambiental (que culmina en la consiguiente declaración de impacto) ha de realizarse también con carácter previo al otorgamiento de la correspondiente autorización ambiental: sólo así la administración actuante está en grado de tomar en consideración y ponderar los valores ambientales presentes antes de adoptar la correspondiente resolución".

A mayor abundamiento, el TS aduce también la doctrina constitucional del TC que, definida, por todas, en la Sentencia 13/98, de 22 de enero, permite entrever que la finalidad propia de la evaluación del impacto ambiental "es facilitar a las autoridades competentes la información adecuada, que les permita decidir sobre un determinado proyecto con pleno conocimiento de sus posibles impactos significativos en el medio ambiente".

A resultas de todo lo anterior, al haberse practicado la declaración de impacto ambiental en la misma fecha que lleva la autorización ambiental integrada, no cumple sino concluir que en el supuesto de autos no se han satisfecho las exigencias legalmente requeridas. Porque, como resulta incuestionable, debe ponderarse la declaración de impacto emitida por el órgano ambiental competente y a continuación decidir si ha de otorgarse o denegarse la 
autorización ambiental integrada o sujetar ésta a determinadas condiciones. Y como quiera que se ha otorgado la autorización ambiental integrada en la misma fecha en que se emitió la declaración de impacto, resulta imposible que en el mismo día la Administración autonómica haya podido realizar la ponderación a que estaba emplazada de acuerdo con lo expuesto.

Llegados a este punto, en efecto, no cabe ya discusión posible sobre el hecho de que la declaración de impacto ambiental ha de ser previa a la resolución autorizatoria y ha de publicarse igualmente con carácter previo. Pues bien, a juicio del TS, el eslabón de la cadena que falta y que sirve de nexo de unión entre ambas exigencias es, precisamente, el que sigue, a saber, en los casos que nos ocupan, la declaración no sólo ha de ser previa a la autorización y ha de hacerse pública, sino que, además, la publicación de la declaración ha de efectuarse con carácter previo al otorgamiento de la autorización. Para ello, el máximo órgano jurisdiccional argumenta en primer término que

“el hecho mismo de exigir la publicación previa de la declaración vendría así a asegurar y a acreditar sin discusión posible ya que el otorgamiento de la autorización se produce con posterioridad; lo que en cambio resultaría más difícil de garantizar si nada impidiera que la publicación de la declaración pudiera realizarse con posterioridad."

De otro lado, y desde el punto de vista estrictamente sustantivo, porque "(d)icha declaración mira, desde luego, a informar a la administración actuante de los valores ambientales concurrentes en el caso y a ilustrarle sobre tales valores en punto a la resolución que corresponda adoptar".

Y finalmente, y en atención a una perspectiva procedimental,

"con la declaración de impacto no culmina el procedimiento y queda éste pendiente solo del otorgamiento de la autorización ambiental; por el contrario, esta fase ha de tener continuidad en una fase sucesiva, de carácter también sustantivo, con miras a ponderar la procedencia de otorgar la autorización ambiental y de determinar, en su caso, las condiciones a que ha de supeditarse su otorgamiento".

Pero lejos de concluir el análisis del TS, al máximo órgano jurisdiccional 
todavía le falta por abordar un último aspecto de gran interés. Así pues, y como quiera que,

"la configuración del trámite de evaluación, por consiguiente, reclama en estos casos la prosecución del procedimiento y la apertura de una nueva fase tras la declaración. Y esta segunda fase solo puede adquirir relieve sustantivo si la declaración se pone en conocimiento de todos. La declaración busca así igualmente informar al público en general de la existencia de tales valores ambientales, difundirlos y darles publicidad, en definitiva, ponerlos en circulación y fomentar de este modo la participación ciudadana".

El acceso del público en general a la información ambiental y, en este concreto caso, la participación ciudadana en la toma de decisiones con incidencia ambiental resulta absolutamente determinante para la suerte que puedan correr los derechos de los recurrentes. Porque tal y como destaca el TS,

“(e)n las distintas fases en que se divide el procedimiento encaminado a la obtención de la autorización ambiental integrada, así, pues, los interesados han de poder participar y formular las correspondientes alegaciones. La participación y la información constituyen sendos pilares esenciales del trámite de evaluación de impacto ambiental y la emisión de la declaración de impacto constituye una fase relevante, de manera que si su texto definitivo no se somete a información ni a participación se desatienden ambos principios... porque sólo si se procede con carácter previo a la publicación de la declaración de impacto ambiental podrá llegar a alcanzarse también a satisfacer esta finalidad”.

Todo lo anterior conduce a la estimación del motivo de casación y, sin necesidad de examinar los restantes motivos, a casar la Sentencia de instancia, y anular la resolución recurrida. Estas mismas consideraciones son las que finalmente llevan a la estimación del recurso contencioso-administrativo

\section{Ordenanza municipal y límite de emisiones de los vehículos autotaxi.}


La Sentencia núm 564/2017, de la Sala de lo contencioso-administrativo del TSJM, de 17 de julio de 2017, resuelve el recurso contencioso-administrativo interpuesto por la Asociación de empresarios madrileños del taxi contra determinados preceptos el Acuerdo del Pleno del Ayuntamiento de Madrid de 28 de noviembre de 2012, por el que se aprueba la Ordenanza Reguladora del Taxi.

En atención a la finalidad de esta crónica de jurisprudencia de dar cumplida cuenta de aquellos pronunciamientos judiciales más destacados en estricta perspectiva ambiental, del amplio objeto de la controversia, al resultar impugnados numerosísimos artículos de la Ordenanza municipal, interesa ahora sólo recrear las circunstancias puramente ambientales de ese recurso contencioso-administrativo.

En este sentido, la Asociación demandante recurre, en primer término, el artículo 16 y la Disposición Transitoria Segunda de la Ordenanza por una eventual infracción del Derecho de la UE y de la Jurisprudencia del Tribunal de Justicia de la Unión Europea. El primer precepto discutido tiene el siguiente tenor literal:

"1. Los vehículos no podrán superar la antigüedad de 10 años contados desde su primera matriculación, cualquiera que sea el país donde ésta se hubiere producido.

2. Las emisiones del vehículo no podrán superar los $160 \mathrm{~g} / \mathrm{km}$. de $\mathrm{CO}_{2} \mathrm{ni}$ los límites de la Norma Euro 6, en lo que respecta a emisiones de contaminantes locales".

Mientras que la citada Disposición Transitoria Segunda preceptúa que

1. Hasta el 1 de enero de 2020 serán denominados vehículo "ecotaxi" aquellos vehículos cuyas emisiones sean inferiores a $160 \mathrm{~g} / \mathrm{Km}$. de $\mathrm{CO}_{2}$ y $80 \mathrm{mg} / \mathrm{Km}$. de NOx.

2. El Ayuntamiento de Madrid fomentará la adquisición y uso de los ecotaxis estableciendo las siguientes medidas: 
a) Podrán ser eximidos de las características exigidas en el artículo 17 de esta Ordenanza.

b) Podrán establecerse puntos de parada de uso exclusivo.

c) Podrán circular sin las limitaciones que se establezcan en circunstancias de restricción de la circulación, por motivos de contaminación.

Para que sea de aplicación lo dispuesto en los apartados anteriores, los ecotaxis deberán llevar el distintivo correspondiente para su identificación previsto en el Anexo II que será expedido por el Ayuntamiento de Madrid.

3. A partir del 1 de enero de 2014 , no se autorizarán nuevos modelos de vehículos auto-taxi que superen los límites de emisiones establecidas en el apartado anterior.

4. A partir del 1 de enero de 2015, no se autorizará a los titulares de licencia la sustitución de vehículos por otros que superen los indicados límites de emisiones.

5. A partir del 1 de enero de 2020, no podrán prestar servicio los vehículos auto-taxi que superen los límites indicados en el artículo 16.

6. No obstante lo dispuesto en el apartado anterior, los vehículos adquiridos antes de la entrada en vigor de la presente Ordenanza, podrán prestar servicio hasta completar el plazo de antigüedad de diez años.

A juicio de la recurrente, los preceptos citados infringen el Reglamento CE 715/2007, de 20 de junio, sobre la homologación de tipo de los vehículos de motor por lo que se refiere a las emisiones procedentes de turismos y vehículos comerciales ligeros (Euro 5 y Euro 6). Al venir referido el artículo 16 de la Ordenanza a la norma Euro 6 sobre emisiones, hay que tener en cuenta que esta norma no resultaba exigible desde la fecha de publicación de la ordenanza sino desde el 1 de septiembre de 2014, por lo tanto, no puede entenderse que 
infringiera el Reglamento CE 715/2007, de 20 de junio.

Y no hay infracción de la norma reglamentaria europea, en el parecer del TSJM dado que

"se remite a la aplicación de la normativa euro 6 desde la entrada en vigor de la ordenanza cuando se solicita la adscripción de un vehículo a una determinada licencia. Es decir, adelanta para los vehículos dedicados al servicio de auto-taxis la aplicación de la mencionada norma, lo que no resulta contrario al derecho comunitario puesto que los estándares en materia medioambiental establece un contenido mínimo que no puede ser modificado a la baja, pero en ningún caso, se trata de un establecimiento máximo de forma que resulta permisible que los estados y las administraciones correspondientes puedan ser más exigentes en los requisitos ambientales como ocurre en el caso presente, cuando el Ayuntamiento de Madrid adelanta la aplicación de la norma al calendario establecido en el reglamento (CE) 715/2007 del Parlamento Europeo y del Consejo, de 20 de junio de 2007".

Y por esta misma razón, tampoco es contraria al Derecho de la UE la previsión de la Disposición Transitoria Segunda cuando establece que a partir del 1 de enero de 2020 no podrán prestar servicio los vehículos auto-taxi que superen los límites indicados en el artículo 16. Aunque tal medida implique la retirada de la circulación de los vehículos cuya primera matriculación sea posterior al 31 de diciembre de 2009, entre los que se encontrarán los vehículos que no cumplan con la norma Euro 6, se trata de una mejora respecto de las previsiones del Reglamento CE 715/2007. Y este tipo de mejoras normativas son perfectamente compatibles con el Derecho de la UE. A lo que se suma el hecho, para nada irrelevante, de que la medida en cuestión se enmarca en el ámbito de la protección del medio ambiente, materia sobre la cual el Ayuntamiento de Madrid tiene competencias normativas conforme al artículo 25.2.f) de la Ley $7 / 1985$, de 2 de abril, reguladora de las bases del régimen local en los términos de la legislación del Estado y de las Comunidades Autónomas, y con respaldo último en la Directiva 2008/50, de 21 de mayo. Sin poder perderse de vista, en última instancia, que los auto-taxis son vehículos cuya circulación se realiza preferentemente por el municipio, de forma además 
mucho más intensiva que el resto de los turismos de uso particular, y gozando de medidas de las que no disponen estos, como son los carriles exclusivos.

Finalmente, el recurso contencioso-administrativo también se dirige contra el artículo 21 de la Ordenanza reguladora del taxi que establece que los vehículos calificados como accesibles o adaptados cumplirán las condiciones y requisitos establecidos en la legislación sectorial correspondiente, por lo que no les será exigible el cumplimiento de los límites de emisiones contenidos en el artículo 16 que, recuérdese, indica que las emisiones del vehículo no podrán superar los $160 \mathrm{~g} / \mathrm{km}$. de $\mathrm{CO}_{2}$ ni los límites de la Norma Euro 6, en lo que respecta a emisiones de contaminantes locales.

Pues bien, el Ayuntamiento de Madrid, justifica dicha decisión en que la justificación para eximir a los "eurotaxis" de los límites de emisiones contenidos en el artículo 16, tiene su justificación en que actualmente no existe ningún vehículo accesible que cumpla las emisiones contenidas en el citado artículo, por lo que si no se estableciera la excepción se daría la paradoja de que no habría ningún vehículo adaptado que pudieran adquirir los titulares de licencia para prestar este servicio. Y como reconoce y sostiene el propio TSJM, "(e)n este caso, ha primado la importante función social que realizan los eurotaxis como medio para el transporte de personas discapacitadas sobre los criterios contenidos en el Plan de Calidad del Aire sobre los límites de emisiones de vehículos".

En lógica consecuencia y, como ya se ha expuesto en relación con el análisis del artículo 16, no existe, por tanto ahora, infracción de la norma comunitaria, estando también justificada la regulación dadas las características especiales de dichos vehículos, que son las que precisamente determinan que al tiempo de dictarse la ordenanza no existieran en el mercado vehículos homologados para el trasporte de personas con necesidades especiales y que justifica la norma más aún en atención a lo dispuesto en el artículo 49 CE.

En definitiva, y por lo que se refiere a la impugnación de los artículos 16 (más Disposición Transitoria segunda) y 21 , finalmente la misma no resulta estimada por el TSJM. 